\title{
Latent Tuberculosis: Advances in Diagnosis and Treatment
}

\author{
Dimitrios Basoulis, Georgia Vrioni, Violetta Kapsimali, \\ Aristeidis Vaiopoulos and Athanasios Tsakris \\ Medical School of the National and Kapodistrian University of Athens
}

Greece

\section{Introduction}

Tuberculosis (TB) is one of the oldest diseases known to affect humans. It is caused by bacteria belonging to the Mycobacterium tuberculosis complex and strains of these bacteria have been found in human bones dated from the Neolithic era. It was known to the ancient Greeks, Indians and the Inca, making it a disease with a global distribution even from ancient times. Latent tuberculosis infection refers to a time period where the host has been exposed and infected by the bacteria yet does not exhibit any signs or symptoms of infection. It is estimated that one third of the world, almost 2 billion people suffer from latent tuberculosis infection.

\section{Epidemiology}

Tuberculosis is a multisystemic infection with myriad presentations and manifestations. According to the World Health Organization (WHO) it is estimated that one third of the world's population is currently infected by the bacillus and out of those people $5-10 \%$ will exhibit symptoms at some point during their life. WHO estimates that the largest number of new TB cases in 2008 occurred in the South-East Asia Region, which accounted for 35\% of incident cases globally. However, the estimated incidence rate in sub-Saharan Africa is nearly twice that of the South-East Asia Region with over 350 cases per 100000 population (WHO, 2011). Tuberculosis remains the most common cause of infectious disease related mortality worldwide. It is evident by this alone that latent tuberculosis is a serious public health problem, not only due to the possibility of the patients themselves eventually developing active tuberculosis, but also because of the public health risk that they impose.

M. tuberculosis is most commonly transmitted from a patient with infectious pulmonary tuberculosis via droplet nuclei, aerosolised by coughing, sneezing or even speaking. The tiny droplets dry rapidly, but the smallest of them $(<10 \mu \mathrm{m}$ in diameter) can remain suspended in the atmosphere for several hours. When inhaled, these droplets can reach the terminal airspaces of the lung. Risk factors for transmission include the proximity of contact, the duration of contact, the degree of infectiousness of the case and the shared environment of the contact. It needs to be noted that patients that have sputum smear negative and culture positive tuberculosis are less infectious, whereas patients with culture negative 
sputum pose essentially no risk for transmission. It is estimated that up to 20 people can be infected by a single patient before tuberculosis can be identified in high prevalence countries. Transmission is more common in tightly packed populations (i.e. overpopulated areas, military personnel etc.) in countries with a higher incidence.

It has been demonstrated that large clusters of TB are associated with an increased number of tuberculin skin test-positive contacts, even after adjusting for other risk factors for transmission. The number of positive contacts was significantly lower for cases with isoniazid-resistant TB compared with cases with fully-susceptible TB. This result has been interpreted to imply some connection between isoniazid resistance and mycobacterial virulence (Verhagen et al., 2011).

After exposure to the bacteria, the patient has a 5-10\% chance of developing active tuberculosis. Risk factors that determine this progression include age, the individual's innate susceptibility to disease and level of function of cell-mediated immunity. Clinical illness directly following infection is classified as primary tuberculosis and is more common in children. The majority of patients infected will develop disease within a year while the rest will develop latent tuberculosis. Activation of tuberculosis bacilli at any point thereafter is termed secondary tuberculosis. Several diseases predispose the patient to develop active tuberculosis with chief amongst them HIV co-infection. It is estimated that nearly all of infected individuals that are HIV positive will at some point develop active tuberculosis; this risk depends on the level of immunosuppression and the CD4+ cell count of the infected patient. Patients with diabetes have 2-5 times increased risk for developing active disease, whereas the relative risk for patients with chronic renal failure climbs to $10-25$.

\section{Pathophysiology of tuberculosis infection}

Two models for the pathophysiology of tuberculosis infection and the formation of granulomas have been suggested. The first one is the static model and it is considered to be the traditional one. The second was suggested a few years ago and it is the dynamic model of infection.

\subsection{The static model}

Mycobacteria belong to the family Mycobacteriaceae and the order Actinomycetales. The most important member of the Mycobacterium tuberculosis complex is the namesake organism, Mycobacterium tuberculosis. The complex also includes M. bovis (the bovine tubercle bacillus), M. africanum (isolated from cases in West, Central and East Africa), $M$. microti (a less virulent rarer bacillus), M. pinnipedii and $M$. canettii (very rare isolates). $M$. tuberculosis is a slow-growing, obligate aerobe and obligate pathogen. Most often, it is neutral on Gram's staining, however, once stained, the bacilli cannot be de-colorised by acid alcohol, hence the characterization as acid-fast and the reason they are best seen using the Ziehl-Neelsen stain. This ability of mycobacteria is derived from the high content of mycolic acids, long chain fatty acids and other lipids found in abundance in the cell wall of mycobacteria (Harada, 1976; Harada et al, 1977). In the mycobacterial cell wall, lipids are linked to underlying arabinolactan and peptidoglycan, which confers a high resistance to antibiotics due to low permeability of this structure. Another element of the cell wall structure is the lipoarabinomannan which is crucial to the mycobacterium's survival within 
the host's macrophages. All of these proteins, characteristic of M. tuberculosis are included in the purified protein derivative (PPD, a precipitate of non-species-specific antigens obtained from filtrates of heat-sterilised, concentrated broth cultures.

The majority of inhaled bacilli are trapped at the level of the upper airways and expelled. A small fraction $(<10 \%)$ will descend further down the bronchial tree. When the inhaled droplet nuclei reach the terminal airspaces of the lung, the bacilli, transported with the droplets, begin to grow for 2-12 weeks before any immune response from the host can be elicited. The host's immune system responds when the bacillary load reaches 1000-10,000 cells. Non-specifically activated alveolar macrophages will eventually begin to ingest the bacilli and sequester them from the host.

Phagocytes have 2 methods of dealing with the mycobacteria. Fusing the phagosomes containing the mycobacteria with lysosomes they create phagolysosomes. Phagolysosomes are the product of a fusion-fission process between the lysosomes, the phagosomes and other intracellular vesicles. The $\mathrm{Ca}^{+2}$ signalling pathway and recruitment of vacuolar-proton transporting ATPase (vH+-ATPase) lead to a decrease in the $\mathrm{pH}$ of the phagolysosome, that in turn allows acid hydrolases to function efficiently for their microbicidal effect. Another way that phagocytes deal with the mycobacteria is through ubiquitination of mycobacterial cell wall and membrane components, which in turn leads to increased susceptibility to nitric oxide produced by the phagocytes. This process leads to phagocyte apoptosis (Beisiegel et al 2009; Bermudez \& Goodman, 1996; Chan \& Flynn, 2004; Cooper, 2009; Pieters, 2008; Ahmad, 2010).

This form of defence, however, proves inefficient as the bacilli have the ability to survive inside the macrophages by modulating the behaviour of its phagosome, preventing its fusion with acidic, hydrolytically-active lysosomes (Pieters, 2008; Russel et al 2009) The escape of $M$. tuberculosis from macrophage destruction is dependent on the 6-kDa early secreted antigenic target (ESAT-6) protein and ESX-1 protein secretion system encoded by the region of difference 1 (RD1). The ESAT-6 protein associates with liposomes containing dimyristoylphosphatidylcholine and cholesterol and causes destabilization and lysis of liposomes. It can also infiltrate the phagosome's membrane and cause lysis of the phagosome, enabling the mycobacteria to escape (Brodin et al, 2004; de Jonge et al, 2007; Derrick \& Morris, 2007; Kinhikar et al, 2010).

In this initial stage of interaction, either the macrophages manage to contain the bacillary reproduction through sequestration and production of cytokines and proteolytic enzymes, or the bacilli manage to survive and multiply, leading to macrophage lysis. Through chemotaxis, monocytes arrive at the site of infection to ingest the bacilli after the macrophage lysis. Either through lysis or apoptosis the mycobacterial antigens are exposed and presented to $\mathrm{T}$ lymphocytes that will carry out the burden of the host's immune response orchestration.

Following these events, the host's immune system activates two more mechanisms to battle the invading bacteria: a tissue damaging response and a macrophage activating response. The tissue damaging response is a delayed-type hypersensitivity reaction to bacillary antigens leading to the destruction of "infected" macrophages. The macrophage activation focuses on activating specific macrophages to ingest and destroy the bacteria. Local macrophages are activated when the non-specific macrophages present bacillary antigens to 
T lymphocytes, stimulating them to release lymphokines. Depending on which one of the two mechanisms is predominant, the subsequent form of tuberculosis is determined.

If the macrophage activation predominates, large numbers of activated macrophages arrive at the site of infection and granulomatous lesions begin to form. During this early stage and under the influence of a vascular endothelial growth factor (VEGF), the granuloma becomes highly vascularised which in turn will provide the pathway for the lymphocytes and macrophages to arrive at the site (Alatas F et al, 2004) Once there, the macrophages will further differentiate into different cells such as multi-nucleated giant cells, epitheliod cells and foamy macrophages. These cells will form the outer wall of the granuloma, now dubbed tubercle. The structure becomes much more stratified and a fibrous cuff forms outside the macrophage layer. Lymphocytes move away from the centre and aggregate outside this fibrous layer (Cáceres et al 2009).

The tissue damaging response on the other hand leads to destruction of macrophages that fail to contain the bacilli and in turn creates a necrotic area at the centre of the tubercle with dead macrophages. Due to low oxygen, presence of nitric oxide, nutrient deficiency and very acidic $\mathrm{pH}$ the mycobacteria cannot continue to multiply inside the tubercle centres, yet they can survive and remain dormant (Ahmad, 2010; Ohno et al, 2003; Voskuil et al, 2003). The central necrotic region resembles cheese in texture and has granted the name caseous necrosis to this process. At this point, some of the tubercles calcify and heal while others evolve further.

Two distinct types of granulomas have been identified. The classic caseous granulomas are composed of epithelial macrophages, neutrophils, and other immune cells surrounded by fibroblasts. M. tuberculosis resides inside macrophages in the central caseous necrotic region. The second type of granulomas (fibrotic lesions) is composed of mainly fibroblasts and contains very few macrophages. The exact location of viable $M$. tuberculosis in these lesions is not known (Barry et al, 2009). It needs to be noted that even the healed, fibrotic tubercles can still contain mycobacteria in a dormant state.

It has been suggested that the caseating centre of the granuloma is not the site where the host's immune response is organized and maintained, but rather that site is at the outer layers of the tubercle, where the macrophages can present their antigens to the lymphocytic population of the tubercle. This formation resembles a secondary lymphoid organ and is theorised to be better suited to orchestrate the host's immune response, as suggested by the high proliferative activity only observed in peripheral follicle-like structures (Ulrichs et al, 2004).

If the tissue damaging response predominates, due to a week response from the macrophages, the initial lesion cannot be contained and continues to grow at the expense of the surrounding tissue. Bronchial walls and blood vessels are destroyed in this process (hence why haemoptysis is a chief symptom in rampant tuberculosis) and cavities are gradually formed (Zvi et al, 2008).

The mycobacterial cell wall components are recognized by host receptors that include tolllike receptors (TLRs), nucleotide-binding oligomerisation domain (NOD)-like receptors (NLRs), and C-type lectins, including mannose receptor (MR), the dendritic cell-specific intercellular adhesion molecule grabbing nonintegrin (DC-SIGN), macrophage inducible Ctype lectin (Mincle) and dendritic cell-associated C-type lectin-1 (Dectin-1). The TLR 
signalling is the main arm of the innate immune response and M. tuberculosis phagocyted through different receptors may have a different fate (Harding \& Boom, 2010; Ishikawa E et al, 2009; Jo, 2008; Jo et al, 2007; Noss et al, 2001).

Cell mediated immunity, more specifically macrophages and CD4+ T lymphocytes, plays a very important role in the above process. The infected macrophages produce a host of cytokines: Interleukin 1 (IL1) which leads to the development of fever, interleukin 6 (IL6) which leads to hyperglobulinemia and tumour necrosis factor a (TNF-a) that contributes to the killing of mycobacteria, the formation of caseating granulomas, fever and weight loss. As mentioned earlier, non-specific macrophages are also responsible for presenting the bacillary antigens to the T cells and eliciting their response (Khader \& Cooper, 2008; Kursar et al 2007). Activated T helper Type 1 lymphocytes participate in the destruction of infected cells through an MHC class II restricted process. They also produce interferon $\gamma$ (IFN- $\gamma$ ) and interleukin 2 (IL2) and promote cell-mediated immunity. Once the bacillary growth is stabilized, the presence of CD8+ T cells appears to gain importance, both for the production of IFN- $\gamma$ and an increase in the cytotoxic activity. This is a period of stalemate where the bacillary load remains relatively constant and the infection is in a state of latency (Bodnar et al, 2001; Russel et al, 2009).

More recently, it was demonstrated that IL1-beta, a subset of interleukin 1, which plays an important part as mediator in the host's immune response, is induced when ESAT- 6 is secreted from the bacilli. IL1-beta is activated through the inflammasome, a caspase activating protein complex. Caspases are cysteine-aspartic proteases that play a part in inflammation response and apoptosis. Mycobacteria have developed the ability to halt the inflammasome's formation by secreting a $\mathrm{Zn}^{+2}$ metalloprotease, encoded by the zmp1 gene. Mycobacteria genetically modified for zmp1 deletion and through the secretion of ESAT- 6 lead to IL1-beta activation and elicit a stronger immune response from the host leading to improved mycobacterial clearance by macrophages, and lower bacterial burden in the lungs of aerosol-infected mice (Danelishvili, 2010; Lalor, 2011; Master 2008; Mishra, 2010). Mycobacteria secrete their own enzymes (Rv3654c and Rv3655c) within the macrophage cytoplasm with the ability to cleave caspase-8. In this manner, the bacilli prevent macrophage apoptosis by preventing the inflammasome's formation and promote cellular lysis (Danelishvili, 2010). It has been demonstrated that it is more beneficial to bacterial growth if the macrophages are steered towards lysis as opposed to apoptosis. Necrosis was correlated with Caspase 3 activity and bacterial growth, whereas activation of calcium, TNFalpha and Caspase 8 was associated with apoptosis and decreased bacterial load (Arcila et al, 2007).

Humoral immunity seems to play a much lesser role if any. The evidence that B-cells and $\mathrm{M}$. tuberculosis-specific antibodies can mediate protection against extracellular M. tuberculosis is highly controversial as their contribution is probably of minor importance (TBNET, 2009).

The host's immune response can eventually cause more problems through tissue destruction and uncontrolled activation of macrophages and lymphocytes. For this reason there is a negative feedback mechanism in place, to control the extent of the response. A family of receptor tyrosine kinases provide this negative feedback mechanism to both, TLR-mediated and cytokine-driven proinflammatory immune responses (Liew, 2005). Again, the mycobacteria have developed mechanisms to take advantage of this process in order to halt the immune response to their benefit. Several M. tuberculosis cell wall components or protein 
products such as 19-kDa lipoprotein, glycolipids (particularly Man-LAM), trehalose dimycolate (cord factor) can modulate antigen-processing pathways by MHC class I, MHC class II and CD1 molecules, phagolysosome formation and other macrophage intracellular signalling pathways (Ahmad, 2010; Bowdish et al, 2009; Gehring et al, 2004; Harding \& Boom, 2010; Jo et al, 2007; Nigou et al, 2001; Noss et al, 2001; Pecora et al; 2006). This results in a subset of macrophages that are unable to present mycobacterial antigens to $\mathrm{T}$ lymphocytes

It is hypothesized that the infection sustains itself not through replicating bacilli forming equilibrium with those being destroyed by the host's immune system, but through a population of non-replicating bacilli that can withstand the immune response. The evidence to this is indirect, suggested by the lack of cellular debris in the granuloma centres of infected mice (Rees \& Hart, 1961). It is believed that the host's immune response is driven by antigens produced during active multiplication of the bacilli and thus, those that remain dormant would not sustain that response to its maximum potential (Andersen, 1997).

\subsection{The dynamic model}

More recently a dynamic model of infection was proposed able to give some logical explanations to some short-comings of the static model. The first question posed was how it is possible for the mycobacteria to remain dormant in the tubercle environment when the host is trying to re-structure the damaged tissues. The alveolar macrophages have a lifespan of 3 months, yet according to the static model, they exist in stalemate with the mycobacteria for a much longer period of time, whether as part of the middle layer of the granuloma or as part of the caseous centre having phagocyted bacilli and sustaining them in their dormant state (Cardona, 2009).

The second question was how did the bacilli reactivate themselves from their dormant state, as it has been demonstrated that the resuscitation factors necessary for this are only produced by active bacilli (Cardona, 2009; Shleeva et al, 2002).

The third question posed seeks an explanation based on a physiological model regarding the ability of isoniazid to treat latent tuberculosis when it is known that isoniazid can only take effect on actively multiplying bacilli (Cardona, 2009; TBNET, 2009).

According to the dynamic model that has been suggested, the granulomas are not static formations but rather, inside the granuloma, there exists a balance between inactive dormant bacilli, rapidly multiplicating ones, dying bacilli and cellular debris constantly being removed from the site (TBNET, 2009). The exact nature of the metabolic state of mycobacteria within the macrophages in the granuloma is a matter of great debate and investigation.

The size of the actively multiplicating mycobacterial load in the granuloma determines the antigen-specific re-stimulation of memory $\mathrm{T}$ lymphocytes. On the other hand, if the mycobacteria are mostly contained within macrophages in their dormant state, it is more likely that $\mathrm{T}$ cell immunity will begin to decline. This in turn would explain why a tuberculin skin test can revert to negative after exposure at a rate of about $5 \%$ per year (TBNET, 2009). 
Perhaps the most important element in this proposed model is the role of the foamy cell, i.e. alveolar macrophages at the end of their life cycle and filled with lipids, due to phagocytosis of extracellular debris, mostly consisting of lipid-rich cellular membrane remains. The mycobacteria phagocyted by these cells can survive through the mechanisms explained earlier. The dynamic model suggests that the mycobacteria can continue to grow albeit at very slow rates instead of becoming dormant. The slower metabolic rate provides resistance to stress and reduces the nutritional needs of the bacilli, thus allowing their survival (Cardona, 2009; Muñoz-Elias et al, 2005). It has not been fully researched but evidence suggests that mycobacteria can escape the phagosomes of the foamy cells and reach the bronchial tree and become aerosolised.

Foamy cells provide a stressful environment that conditions the bacilli to become more resistant. This in turn, confers them the ability to better survive in the open air and according to some studies explains why they are more virulent. Moreover, the high lipid content of the foamy cells also provides triglycerides to the bacilli that will in turn provide them with nutrients in new infection sites in the event of starvation. In fact the highly aggressive Beijing strains have also been found to contain large amounts of lipids, which would at least partly account for the greater virulence (Garton et al, 2002; Neyrolles et al, 2006; Peyron et al, 2008). Finally the high lipid content of foamy cells when exposed to the alveolar spaces will contribute to increased surfactant concentration and thus will make aerosolisation of the bacteria easier (Cardona, 2009).

Growing bacteria are easy to combat since they cannot survive in stressful environments. The dynamic model offers a different explanation of the mechanism, with which the host's immune system focuses on the non-replicating bacteria. The phagocyted bacilli, as explained in the static model, will eventually lead to lysis or apoptosis of the macrophages. This cellular debris and the extracellular bacteria will form the population of the non-replicating bacteria at the caseous centre. The attraction of specific macrophages and neutrophils will provide a new breeding ground for the active bacteria and also material for the formation of the foamy cells, as they will phagocyte cellular membrane remnants to clear the debris from the caseous centre of the granuloma. The bacilli, inside the foamy cells, under these circumstances, will eventually find themselves within the bronchial spaces and after they are aerosolised they will reinfect the host at new sites. Due to their higher virulence they will manage to overcome the initial immune response and form a new granuloma to repeat the same sequence of events (Cardona, 2009). At the new site of infection the bacilli are actively multiplying again and thus are susceptible to isoniazid. This would explain why a single-drug nine month treatment is effective in most cases of latent tuberculosis.

\section{Latent tuberculosis and reactivation}

Mycobacteria are completely eradicated only in about $10 \%$ of the cases, while in the remaining, the bacilli survive for years to come, through the processes explained. This state has been termed latent tuberculosis infection. In any event where the host's immune response dwindles, there is a risk for the bacilli to reactivate themselves and lead to active tuberculosis infection. Most of the new cases of tuberculosis in low incidence countries are the result of such reactivation of latent tuberculosis infections. It is of interest to note that expression of DosR-regulated dormancy antigens continues even in this latent stage of infection, providing a promising new target for vaccines that would help battle latent TB 
infections in the future (Leyten et al, 2006; Lin \& Ottenhoff, 2008). It is also probable that $M$. tuberculosis, during the latent stage of infection can form spore-like structures, typically seen with other mycobacteria, in response to prolonged stationary phase or nutrient starvation, for its survival (Ghosh et al, 2009).

The reactivation of latent infection requires M. tuberculosis to exit dormancy. This is mainly achieved through the effects of a family of five proteins, dubbed resuscitation promoting factors (Rpfs), that have the effect of a lytic transglycosylase. These molecules were found to be able to cause degradation to cell wall components of the mycobacteria. It is not exactly known how this activity relates to the resuscitation process, it is however theorised that the end result of this enzymatic activity is changes to the mycobacterial cell-wall, overcoming the environmental restraints to the bacterial multiplication. Another theory states that the changes brought to the cell wall, lead to production and secretion of peptidoglycans with the ability to modulate the environment and the host's immune response (Hett et al, 2007; Tufariello et al, 2006). It needs be noted that $M$. tuberculosis bacilli found in the sputum of patients with latent infection and after deletion of the Rpfs encoding genes, can only be cultured when Rpfs are introduced to the growth material and thus resuscitation is possible (Mukamolova et al, 2010), however for non-dormant mycobacteria it seems that the Rpfs are not important for their multiplication (Kana et al, 2008).

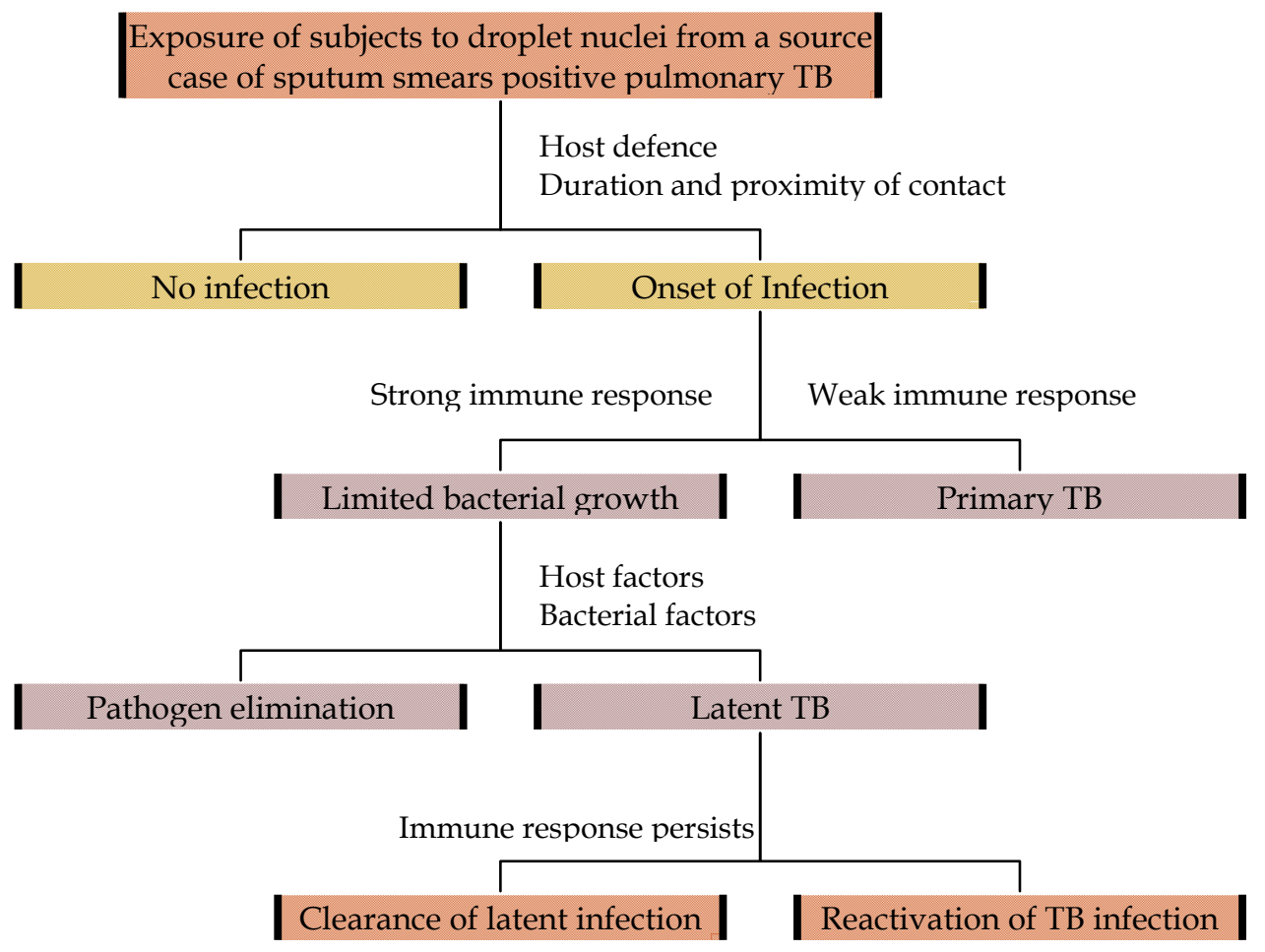

Fig. 1. Natural progression of tuberculosis, adapted from Ahmad, 2010 
It has also been demonstrated that amongst the Rpfs, those that seem to be the most important are RpfA and RpfB. Infected mice with strains of mycobacteria with deletion of the genes encoding these specific Rpfs, were found to be more resistant to TB reactivation and also their macrophages were found to produce larger quantities of TNF-a and IL6 (Russel-Goldman et al, 2008). These resuscitation factors are another possible target for future vaccines against latent TB (Zvi et al, 2008).

\section{Latent tuberculosis diagnosis}

Diagnosis of latent tuberculosis is a matter of active current research due to the difficulties presented in identifying patients with latent infection. There is no question that controlling contacts and identifying people who are carrying the bacilli would be the best prevention plan. However, due to the lack of any physical signs or symptoms and the fact that all or most of the bacilli during this state remain dormant, it is very difficult to elicit an immune system response that would be evident to the observer. This in turn means that it is difficult to identify individuals with latent infection. An ideal test for latent tuberculosis infection diagnosis should meet the following criteria:

- High sensitivity in all populations at risk.

- High specificity regardless of BCG vaccination and infection with environmental mycobacteria.

- $\quad$ Reliability and stability over time.

- Objective criteria for positive result, affordability and easy administration.

- Ability to distinguish recently infected individuals with increased risk of progression to active tuberculosis.

There are currently two groups of tests for latent tuberculosis infection diagnosis: tuberculin skin tests (TST) and interferon-y release assays (IGRA).

\subsection{The tuberculin skin test}

Historically, the most accurate method for detecting if an individual had come in contact with M. tuberculosis was the tuberculin skin test (TST). This test measures the hosts' in vivo immune response in the form of a cell-mediated delayed hypersensitivity reaction to a mixture of more than $200 \mathrm{M}$. tuberculosis antigens, termed as purified protein derivative (PPD). The PPD is a crude mixture of antigens, not specific to $M$. tuberculosis, but also found in other mycobacteria such as the BCG bacillus, $M$. bovis and even non-tuberculous mycobacteria. This mixture is intradermally injected, usually at the inner side of the forearm and the test result is read as an induration on the site of injection after 48-72 hours (Huebner et al 1993). This reaction may last for up to 1 month, depending on the quality and quantity of the initial reaction. Strong reactions may result in tissue necrosis, which is the only absolute contraindication to the TST (TBNET, 2009). The induration is caused due to the introduction of the antigens that causes non-specific neutrophils and antigen-specific $\mathrm{T}$ lymphocytes to arrive at the site and sparkle an inflammatory cascade of cytokine production. The migration of immune cells to the site seems to have a biphasic distribution: an initial nonspecific infiltration where the neutrophils arrive at the site, taking place in the first 4-6 hours and which is an event that also occurs in nonsensitised subjects and a second specific peak, where the specific T cells arrive at the site (Kenney et al, 1987; Platt et al, 1983; 
Poulter et al, 1982; TBNET, 2009). The lymphocyte population is a mix of CD4+ and CD8+ cells with the former being always greater in number (Gibbs et al, 1984). The lymphocytic infiltration is at first perivascular and under the influence of early cytokines, such as IFN- $\gamma$, TNF- $\alpha$ and TNF- $\beta$, the endothelium is stimulating into expressing adhesion molecules (Eselectin), increasing the permeability of the vascular walls and enabling the cells to migrate to the dermis. Regulatory T-cells influence the size of the induration of the tuberculin skin test. Cutaneous CD4 T-cells accumulating after tuberculin PPD stimulation in the skin are predominantly of a CD45 RO memory phenotype (Sarrazin et al, 2009). The criteria for the test's interpretation vary considerably and depend on the nature of the population being tested. They are arbitrary and the result of international consensus.

In the United States, according to the Center for Disease Control (CDC), 5 tuberculin units (TUs) are used and a test is considered positive for the general population with no known TB contacts when the induration measures $15 \mathrm{~mm}$ or more. An induration of 10 or more millimetres is considered positive in recent immigrants ( $<5$ years) from high-prevalence countries, injection drug users, residents and employees of high-risk congregate settings, mycobacteriology laboratory personnel, persons with clinical conditions that place them at high risk, children $<4$ years of age, infants, children, and adolescents exposed to adults in high-risk categories. Finally, an induration of 5 or more millimetres is considered positive in HIV-infected persons, a recent contact of a person with TB disease, persons with fibrotic changes on chest radiograph consistent with prior $\mathrm{TB}$, patients with organ transplants, persons who are immunosuppressed for other reasons (e.g., taking the equivalent of $>15$ $\mathrm{mg}$ / day of prednisone for 1 month or longer, taking TNF-a antagonists, etc.) (CDC, 2011).

In Europe, the situation differs from country to country depending on the incidence and prevalence of TB. In countries with high incidence, such as former Soviet Union countries, a $10 \mathrm{~mm}$ induration is considered positive. In most European countries 2 TUs are used and interpretation of the results follows the same guidelines as in the US (ECDC, 2011).

As with every screening test, TST has a chance of false positive and false negative results. Possible false positive reactions are caused due to infections with non-tuberculous mycobacteria, previous vaccination with BCG, incorrect method of TST administration (including wrong amount of PPD injected as well as injecting it subcutaneously rather than intradermally), incorrect interpretation of reaction (more often than many would assume, doctors and/or nurses measure the erythema caused by the immune response rather than the induration leading to overestimation of the reaction caused), incorrect bottle of antigen used. False negative results are caused by cutaneous anergy (anergy is the inability to react to skin tests because of a weakened immune system, such as in HIV patients or patients under immunosuppression, particularly those taking anti-TNF- $\alpha$ medications for autoimmune conditions), recent TB infection (within 8-10 weeks of exposure), very old TB infection (many years), very young age (less than 6 months old), recent live-virus vaccination (e.g., measles and smallpox), overwhelming TB disease (tuberculosis by itself is thought to cause a degree of immunosuppression to the host in these advanced cases), some viral illnesses (e.g., measles and chicken pox), incorrect method of TST administration, incorrect interpretation of reaction (ECDC, 2011; CDC, 2011).

Of special consideration is the so-called booster effect after TST testing. In certain people, who have been exposed to M. tuberculosis, the ability of their immune system to react to the PPD antigens might have diminished over the course of time. These patients when tested 
with the TST would have a negative reading. However, reintroducing the tuberculosis antigens to their immune system by the test itself stimulates their immune system to react more fiercely to these antigens. Subsequent tests in these individuals would result as positive even though they haven't been exposed to the bacilli in the time between the two tests. In a sense, the first TST "boosted" the results of the second one. In certain populations, the CDC suggests performing a two-step test in order to identify possible false negative first tests and prevent unnecessary treatment. Such populations include health-care workers, doctors, nurses or nursing home residents, whose status with regards to tuberculosis exposure and/or infection is important to know.

It is evident that the TST has several limitations to its use, which in turn sparked the interest in developing new diagnostic tools such as the IGRAs. Such limitations include a high proportion of false positive and false negative results, difficulty in separating true infection from the effects of BCG vaccination and NTM infection, technical problems in administration, immune response boosting after repeated TST, complicated and subjective interpretation and a need for a second visit for the interpretation of the test's result.

\subsection{The interferon-y release assays}

Interferon- $\gamma$ release assay kit tests were developed the past decade as an alternative to the TST. They are whole-blood tests that can aid in diagnosing M. tuberculosis infection, including both latent tuberculosis infection and active disease. They are indirect in vitro, ex vivo tests that measure the production of interferon- $\gamma$ by a patient's $T$ lymphocytes after the latter are incubated with specific $M$. tuberculosis antigens in vitro (Andersen et al, 2000; Harboe et al, 1996; Mahairas et al, 1996). To conduct the test, fresh blood sample from the patient is mixed with the antigens and the response is measured either by measuring the produced interferon through enzyme-linked immunosorbent assay (ELISA), rapid enzymelinked immunospot assay or by measuring the number of activated $\mathrm{T}$ cells through flow cytometry. The difference in method used is what distinguishes the two commercially available kits. QuantiFERON-TB Gold In-Tube (QFT-GIT, by Cellestis Limited, Carnegie, Victoria, Australia) uses the ELISA method and the T-SPOT (by Oxford Immunotec Limited, Abingdon, UK) uses the ELISPOT. It is interesting to mention that initially IGRAs would use the PPD as antigen but still follow the same principle and in an interesting twist of fate, it has been suggested to use the specific IGRA antigens for TST, as these antigens have been found to elicit a distinctive immune response with induration on animals. IGRAs are performed on fresh blood specimens.

The antigens used in these methods are peptides derived from ESAT-6, CFP-10 and for the Quantiferon method TB7.7 proteins of the mycobacteria. The first two are encoded at the region of difference (RD) 1 genetic locum whereas the third at the RD11, regions that are deleted from the $M$. bovis BCG genome and are absent in most environmental mycobacteria, with the exception of M. kansasii, M. szulgai and M. marinum (TBNET, 2009). During earlier stages of the method's development, the entire protein product was used. The early secretory antigenic target (ESAT) is a $6 \mathrm{kDa}$ protein and the culture filtrate protein (CFP-10) is a $10 \mathrm{kDa}$ protein. Together they form an heterodimeric complex and depend on each other for stability. They are secreted through the ESX1 secretion system and are considered to be an indication of virulence. Their role is not fully understood but they seem to induce lysis through integration on the macrophage cellular membrane (Brodin et al, 2004; de Jonge et al, 
2007; Derrick \& Morris, 2007; Kinhikar et al, 2010; Renshaw et al, 2005). Even less is known regarding TB7.7. IGRA techniques support the dynamic model for latent TB since they detect IFN- $\gamma$ produced by $\mathrm{T}$ cells, with a short lifespan that have been activated by macrophages that presented to them the tuberculosis antigens (Cardona, 2009).

For the QFT-GIT (Table 1), $1 \mathrm{ml}$ of blood is drawn into one of each of three special testing tubes. These are precoated and heparinised by the manufacturer. Within 16 hours the tubes must be incubated for another 16 to 24 hours at $37^{\circ} \mathrm{C}$. After centrifugation, the plasma is harvested to be further processed. QFT-GIT collection tubes contain a gel plug that separates the plasma from the cells when centrifuged. The plasma can be used immediately or at a later point in time. Results are interpreted according to the manufacturer's recommendations (ECDC, 2011).

\begin{tabular}{|c|c|c|c|}
\hline \multirow{2}{*}{ Result } & \multicolumn{3}{|c|}{ IFN- $\gamma$ concentration (International Units per ml, IU/ml) } \\
\cline { 2 - 4 } Positive & M. tuberculosis antigens & Nil & PHA \\
\cline { 2 - 4 } Negative & $\geq 0.35 \mathrm{IU} / \mathrm{ml}$ and $\geq 25 \%$ over nil & $\leq 8.0 \mathrm{IU} / \mathrm{ml}$ & Any \\
\cline { 2 - 4 } Indeterminate & $<0.35 \mathrm{IU} / \mathrm{ml}$ or $<25 \%$ over nil & $\leq 8.0 \mathrm{IU} / \mathrm{ml}$ & $\geq 0.5 \mathrm{IU} / \mathrm{ml}$ \\
\cline { 2 - 4 } & $<0.35 \mathrm{IU} / \mathrm{ml}$ or $<25 \%$ over nil & $\leq 8.0 \mathrm{IU} / \mathrm{ml}$ & $<0.5 \mathrm{IU} / \mathrm{ml}$ \\
\cline { 2 - 4 } & Any & $>8.0 \mathrm{IU} / \mathrm{ml}$ & Any \\
\hline
\end{tabular}

Table 1. Quantiferon results interpretation, adapted from ECDC, 2011

For the T-SPOT assay (Table 2), $8 \mathrm{ml}$ of blood are required and the assay must be performed within eight hours of blood collection. Alternatively, the manufacturer also provides a reagent (T-Cell Xtend) which extends processing time to 32 hours after blood collection. The T-cell-containing peripheral blood mononuclear cell fraction is separated from whole blood and distributed to the microtitre plate wells (250,000 cells/well) provided in the assay kit. Following 16 to 20 hours incubation, the number of IFN- $\gamma$-secreting T-cells (represented as spot-forming units) can be detected by ELISPOT assay. As with QFT-GIT the test's results are interpreted according to the manufacturer's recommendations (ECDC, 2011).

\begin{tabular}{|c|c|c|c|c|c|}
\hline \multirow{3}{*}{ Result } & \multicolumn{5}{|c|}{ Spot count } \\
\hline & \multicolumn{3}{|c|}{ M. tuberculosis antigens } & \multirow{2}{*}{ Nil } & \multirow{2}{*}{ PHA } \\
\hline & ESAT-6 & & CFP-10 & & \\
\hline \multirow{3}{*}{$\begin{array}{c}\text { Positive } \\
\text { Negative } \\
\text { Borderline }\end{array}$} & $\geq 6$ over nil & and/or & $\geq 6$ over nil & $\leq 10$ & Any \\
\hline & $\leq 5$ over nil & and/or & $\leq 5$ over nil & $\leq 10$ & $\geq 20$ \\
\hline & \multicolumn{3}{|c|}{ If for any antigen highest is 5 - 7 over nil } & $<10$ & $\geq 20$ \\
\hline \multirow{2}{*}{ Indeterminate } & $\leq 6$ over nil & and & $\leq 6$ over nil & $\leq 10$ & $<20$ \\
\hline & \multicolumn{3}{|c|}{ Any } & $>10$ & Any \\
\hline
\end{tabular}

Table 2. T-Spot results interpretation, adapted from ECDC, 2011 
The presence of negative and positive controls ensures that IGRAs are correctly performed. The three testing tubes contain the mycobacteria antigens (Mtb), no antigens (Nil) and phytohaemagglutinin A (PHA), a T-cell activating mitogen. The Nil vial serves as the negative control for the process whereas the PHA as the positive one. If there is IFN- $\gamma$ production in the Mtb tube, none in the Nil and any amount in the PHA, it means that the result is a positive one because it would imply that the sample's lymphocytes reacted to the antigens as expected and did not react to any other antigens that might have contaminated the sample. If on the other hand there is no IFN-ץ production in the Mtb tube and the Nil tube but there is in the PHA one, it implies that the lymphocytes react normally to the PHA antigen yet they do not react when exposed to the bacilli antigens and therefore these lymphocytes haven't met these antigens before. Finally, the results are indeterminate if at any point there is IFN- $\gamma$ production in the Nil tube, which might imply contamination or there is increased baseline interferon production or if there is no sufficient production in the PHA tube, which might imply anergy. Technical factors (sample collection, storage and transportation) might also contribute to returning indeterminate results (ECDC, 2011).

There is a lot of debate on whether IGRAs are indeed more reliable than the traditional TST. In Germany, Denmark and Switzerland, IGRAs have substituted TST when screening populations receiving anti-TNF-a therapies. The US, Australia, France and Denmark use either TST or IGRAs, whereas Canada, the United Kingdom, Italy, Spain, Australia and Slovakia to name a few, support a 2-step approach using both TST and IGRAs in an attempt to increase sensitivity and specificity of both methods. The two-step approach seems to be the most favoured strategy for IGRA use, especially in BCG vaccinated contacts.

IGRAs have some distinct advantages over TST with regards to diagnosing latent tuberculosis infection. IGRA testing requires a single patient visit to conduct the test and results can be available within the day. Moreover there is no "booster" effect associated with IGRAs since they are ex vivo, in vitro tests. Finally, due to the specificity of the M. tuberculosis antigens used, BCG vaccination does not cause false positive results. Due to the positive control, IGRAs are able to differentiate between immunocompromised hosts and negative results with more accuracy. In the TBNET/ECDC systematic review and meta-analysis (Sester et al. 2010) IGRAs were also found to have greater sensitivity in diagnosing active TB infection compared to the TST, $80 \%$ for QFT-GIT, $81 \%$ for T-Spot compared to only $65 \%$ for the TST. In the same review, specificity was found to be 79\% (75-82\%) for QFT-GIT, 59\% (56$62 \%)$ for T-spot and 75\% (72-78\%) for TST. Sensitivity to diagnose latent TB infection was found $67 \%, 87 \%$ and $71 \%$ for QFT-GTI, T-Spot and TST respectively, whereas specificity for latent TB infection was 99\%, 98\% and 88\% respectively (Diel et al, 2011; Menzies et al, 2007; Pai et al, 2008; Sester et al, 2010).

Current consensus amongst the European countries is that IGRAs can be included in screening for latent TB infection, albeit there is not enough evidence yet to provide a clear picture. Nonetheless it can provide an extra step in establishing a diagnosis. On the other hand, due to their high negative predictive value for immunocompetent patients, negative IGRA results can safely exclude progression to active disease, albeit it does not rule out the possibility of latent infection (Diel et al, 2011). Applying the IGRAs to specimens from possible infection sites (i.e. Bronchoalveolar Lavage) as opposed to blood samples, especially in immunodeficient individuals can help distinguish between active and latent TB (Jafari et al, 2009). In diagnosing active tuberculosis we mention for completeness, that 
current consensus is that IGRAs do not have a place in routine screening, yet in certain cases when there is a strong clinical suspicion yet no laboratory proof, they can contribute. Neither IGRAs nor TST can replace the standard laboratory tools for diagnosing active tuberculosis (ECDC, 2011).

As with the TST, IGRAs also have some shortcomings. Perhaps most importantly IGRAs, just like TST are unable to distinguish between latent and active infection when limited to blood testing. Moreover, blood samples need to be processed within 8-30 hours after collection; otherwise the white blood cells will gradually become non-responsive to the antigenic stimulation. Errors in collecting or transporting blood specimens or in running and interpreting the assay can decrease the accuracy of IGRAs. Since these techniques are relatively new, there is still limited data on the use of IGRAs in certain population groups such as children younger than 5 years of age, HIV patients, anti-TNF-a treated patients or in general immunocompromised patients. Finally there is a significant cost to this process as opposed to the fairly cheap TST method.

Finally, another method is being developed for use that employs flow cytometry for the detection of interferon producing lymphocytes. This method is not yet commercially available and due to the high cost of the process it is not known yet if it will contribute to latent tuberculosis diagnosis (Fuhrmann et all 2008). There are experimental methods detecting antibodies against tuberculosis antigens, but as mentioned already humoral immunity plays a small part in tuberculosis if any at all and thus these methods so far have no clinical application (El-Shazly, 2007). Most recently the WHO issued a statement asking countries to ban antibodies based tests for the diagnosis of tuberculosis (WHO, 2011).

\section{Latent tuberculosis treatment}

Individuals with known contacts with patients suffering from active tuberculosis and who test positive with the aforementioned methods are considered, given reasonable clinical suspicion, to have latent infection. They are eligible to receive treatment in order to prevent them from developing an active infection. In some cases (i.e. children, HIV patients) even without TST or IGRAs supporting, clinical suspicion alone is enough to start treatment and re-test the patient at a later time to verify the result of the diagnostic tests. Treatment for latent tuberculosis is less expensive than for active and preventing the disease provides overall a great economic benefit for the health-care system.

Current guidelines (American Thoracic Society \& CDC, 2000, revised 2005) in the US, suggest a 9-month daily treatment with isoniazid (INH) $5 \mathrm{mg} / \mathrm{kg}$ up to $300 \mathrm{mg}$. This can be reduced to only 6 months, for adults seronegative for HIV co-infection. In most cases the 9 month treatment plan is followed since it has been show to achieve better results $(70 \%$ complete remission vs. $60 \%$ for the 6 month regimen). In very few cases a 12-month regimen is recommended, particularly for populations with a higher incidence of active tuberculosis (TBNET, 2009).

As is the problem with most tuberculosis therapies there is a high amount of non-compliant patients contributing to failure of treatment. One solution would be to enforce Directly Observed Treatment (DOT) for patients taking isoniazid for latent tuberculosis, but such a decision comes with a high financial cost. Under these circumstances, treatment can be modified to a $2 /$ week regimen at a dose of $15 \mathrm{mg} / \mathrm{kg}$ up to $900 \mathrm{mg}$. Isoniazid side-effects 
include polyneuropathy, preventable with administration of B6 vitamin and hepatic toxicity that remains a prime reason for discontinuation of treatment. Studies have shown that $10-$ $20 \%$ of patients will have an increase in liver transaminases and about $2 \%$ will have clinically significant hepatitis, with that percentage increasing in the present of co-morbidity factors (Nolan et al, 1999).

Due to these problems the ATS and CDC have suggested alternative treatment options. One such option is a daily dose of rifampicin (RMP) 4-month single-drug regimen or a daily dose of pyrazinamide (PZA)-rifampicin 4-month regimen. The RMP treatment is not recommended for HIV positive patients due to interactions with HAART treatment, but otherwise it has shown promising results for patients intolerant of INH or for those cases where INH resistance is verified or suspected. Benefits of this shorter regimen include a lower cost and also higher degrees of compliance (Jasmer et al, 2002; Menzies et al, 2004, 2008; Polesky et al, 1996; Reichman et al, 2004; Villarino et al, 1997).

Initially the PZA-RMP regimen was designed to be administered for 2 months, but due to adverse effects (serious hepatotoxicity and death) it is no longer recommended, but for some rare cases (CDC, 2001; Lecoeur, 1989; Gao, 2006) Other possible regimens that are under evaluation include a 3 month daily treatment with INH-RMP and a 3 month weekly INHrifapentin regimen. The former has been tested in the UK and exhibits satisfactory results in terms of adverse effects and success of treatment (Ena \& Valls, 2005). The latter is under study in the US, the CDC recently made public that patients on this regimen have higher compliance, satisfactory remission results compared to INH but it seems that they have increased adverse effects and also the cost of treatment is higher than the RMP regimen.

\section{Conclusion}

Latent tuberculosis is a field of great scientific interest and research possibilities. We have investigated the granuloma and its formation and 2 theories exist, a lot of the secrets still remain hidden and more evidence is needed to support either theory. In the field of diagnosis new tools are available and it remains to be seen how they will fare when tested against special populations (i.e. HIV patients which is the field of our own research as well). New guidelines for treatment are issued and those are under evaluation. Latent tuberculosis is an important public health issue, an insidious infection that can persist for years; above all, clinical suspicion is paramount for its diagnosis.

\section{References}

Ahmad S. (2010) New approaches in the diagnosis and treatment of latent tuberculosis infection Respir Res. Vol 11 No 1 Dec 2010 pp169

Alatas F, Alatas O, Metintas M, Ozarslan A, Erginel S \& Yildirim H.(2004) Vascular endothelial growth factor levels in active pulmonary tuberculosis. Chest. Vol 125 No 6 Jun 2004 pp2156-9

American Thoracic Society, Centers for Disease Control and Prevention. (2000) Targeted tuberculin testing and treatment of latent tuberculosis infection. Am J Respir Crit Care Med. Vol 161 No 4 pt2 Apr 2000 pp221-247

Andersen P, Munk ME, Pollock JM, Doherty TM (2000) Specific immune-based diagnosis of tuberculosis. Lancet Vol 356 No 9235 Sep 2000 pp1099-104 
Andersen P. (1997) Host responses and antigens involved in protective immunity to Mycobacterium tuberculosis. Scand J Immunol. Vol 45 No 2 Feb 1997 pp115-31

Arcila ML, Sánchez MD, Ortiz B, Barrera LF, García LF, Rojas M (2007) Activation of apoptosis, but not necrosis, during Mycobacterium tuberculosis infection correlated with decreased bacterial growth: role of TNF-alpha, IL-10, caspases and phospholipase A2. Cell Immunol. Vol 249 No 2 Oct 2007 pp80-93

Barry CE 3rd, Boshoff HI, Dartois V, Dick T, Ehrt S, Flynn J, Schnappinger D, Wilkinson RJ \& Young D. (2009) The spectrum of latent tuberculosis: rethinking the biology and intervention strategies. Nat Rev Microbiol. Vol 7 No 12 Dec 2009 pp845-55

Beisiegel M, Mollenkopf HJ, Hahnke K, Koch M, Dietrich I, Reece ST, Kaufmann SH (2009) Combination of host susceptibility and Mycobacterium tuberculosis virulence define gene expression profile in the host Eur J Immunol. Vol 39 No 12 Dec 2009 pp3369-84

Bermudez LE, Goodman J (1996) Mycobacterium tuberculosis invades and replicates within type II alveolar cells Infect Immun. Vol 64 No 4 Apr 1996 pp1400-6

Bodnar KA, Serbina NV, Flynn JL (2001) Fate of Mycobacterium tuberculosis within murine dendritic cells. Infect Immun. Vol 69 No 2 Feb 2001 pp800-9

Bowdish DM, Sakamoto K, Kim MJ, Kroos M, Mukhopadhyay S, Leifer CA, Tryggvason K, Gordon S, Russell DG (2009) MARCO, TLR2, and CD14 are required for macrophage cytokine responses to mycobacterial trehalose dimycolate and Mycobacterium tuberculosis. PLoS Pathog.Vol 5 No 6 Jun 2009

Brodin P, Rosenkrands I, Andersen P, Cole ST \& Brosch R. (2004) ESAT-6 proteins: protective antigens and virulence factors? Trends Microbiol. Vol 12 No11 Nov 2004 pp500-8

Cáceres N, Tapia G, Ojanguren I, Altare F, Gil O, Pinto S, Vilaplana C \& Cardona PJ. (2009) Evolution of foamy macrophages in the pulmonary granulomas of experimental tuberculosis models. Tuberculosis (Edinb). Vol 89 No 2 Mar 2009 pp175-82

Cardona PJ. (2009) A dynamic reinfection hypothesis of latent tuberculosis infection. Infection. Vol 37 No 2 Apr 2009 pp80-6 Review

CDC (2001) Update: Fatal and severe liver injuries associated with rifampin and pyrazinamide for latent tuberculosis infection, and revisions in American Thoracic Society/CDC recommendations--United States, 2001. MMWR Morb Mortal Wkly Rep. Vol 50 No 34 Aug 2001 pp733-5

Center for Disease Control TB fact-sheet (n.d) http://www.cdc.gov/tb/publications/factsheets/testing/skintesting.htm

Chan J \& Flynn J. The immunological aspects of latency in tuberculosis. (2004) Clin Immunol. Vol 110 No 1 Jan 2004 pp2-12

Cooper AM Cell-mediated immune responses in tuberculosis. Annu Rev Immunol. Vol 27 2009 pp393-422

Danelishvili L, Yamazaki Y, Selker J, Bermudez LE (2010) Secreted Mycobacterium tuberculosis Rv3654c and Rv3655c proteins participate in the suppression of macrophage apoptosis. PLoS One Vol 5 No 5 May 2010

de Jonge MI, Pehau-Arnaudet G, Fretz MM, Romain F, Bottai D, Brodin P, Honoré N, Marchal G, Jiskoot W, England P, Cole ST \& Brosch R.J (2007) ESAT-6 from M. tuberculosis dissociates from its putative chaperone CFP-10 under acidic conditions and exhibits membrane-lysing activity. Bacteriol. Vol 189 No 16 Aug 2007 pp6028-34 
Derrick SC, Morris SL (2007) The ESAT6 protein of Mycobacterium tuberculosis induces apoptosis of macrophages by activating caspase expression. Cell Microbiol. Vol 9 No 6 Jun 2007 pp1547-55

Diel R, Goletti D, Ferrara G, Bothamley G, Cirillo D, Kampmann B, Lange C, Losi M, Markova R, Migliori GB, Nienhaus A, Ruhwald M, Wagner D, Zellweger JP, Huitric E, Sandgren A, Manissero D (2011) Interferon-y release assays in the diagnosis of latent M. tuberculosis infection. Eur Respir J Vol37 No1Jan2011 pp88-99

ECDC (2011) Guidance Use of interferon-gamma release assays in support of TB diagnosis http://ecdc.europa.eu/en/publications/Publications/1103_GUI_IGRA.pdf

ECDC (2011) Mastering the basics of TB control - Development of a handbook on TB diagnostic methods

http:/ /ecdc.europa.eu/en/publications/Publications/1105_TER_Basics_TB_contr ol.pdf

El-Shazly S, Mustafa AS, Ahmad S \& Al-Attiyah R. (2007) Utility of three mammalian cellentry proteins of Mycobacterium tuberculosis in the serodiagnosis of tuberculosis. Int J Tuberc Lung Dis. Vol 11 No 6 Jun 2007 pp676-682

Ena J \& Valls V (2005) Short-course therapy with rifampin plus isoniazid, compared with standard therapy with isoniazid, for latent tuberculosis infection: a meta-analysis. Clin Infect Dis. Vol 40 No 5 Mar 2005 pp670-6

Fuhrmann S, Streitz M \& Kern F. (2008) How flow cytometry is changing the study of TB immunology and clinical diagnosis. Cytometry A. Vol 73 No11 Nov 2008 pp1100-6

Gao XF, Wang L, Liu GJ, Wen J, Sun X, Xie Y, Li YP (2006) Rifampicin plus pyrazinamide versus isoniazid for treating latent tuberculosis infection: a meta-analysis. Int J Tuberc Lung Dis. Vol 10 No10 Oct 2006 pp1080-90

Garton NJ, Christensen H, Minnikin DE, Adegbola RA, Barer MR (2002) Intracellular lipophilic inclusions of mycobacteria in vitro and in sputum. Microbiology Vol 148 No 10 Oct 2002 pp2951-8

Gehring AJ, Dobos KM, Belisle JT, Harding CV, Boom WH (2004) Mycobacterium tuberculosis LprG (Rv1411c): a novel TLR-2 ligand that inhibits human macrophage class II MHC antigen processing. J Immunol. Vol 15 No 173(4) Aug 2004 pp2660-8

Ghosh J, Larsson P, Singh B, Pettersson BM, Islam NM, Sarkar SN, Dasgupta S \& Kirsebom LA (2009) Sporulation in mycobacteria. Proc Natl Acad Sci U S A. Vol 106 No 26 Jun 2009 pp10781-6

Gibbs JH, Ferguson J, Brown RA, Kenicer KJ, Potts RC, Coghill G, Swanson Beck J (1984) Histometric study of the localisation of lymphocyte subsets and accessory cells in human Mantoux reactions. J Clin Pathol Vol 37 No 11 Nov 1984 pp1227-1234

Harada K (1977) Staining mycobacteria with periodic acid-carbol-pararosanilin: principle and practice of the method. Microsc Acta. Vol 79 No 3 May 1977 pp224-36

Harada K, Gidoh S, Tsutsumi S (1976) Staining mycobacteria with carbolfuchsin: properties of solutions prepared with different samples of basic fuchsin. Microsc Acta. Vol 78 No 1 Mar 1976 pp21-27

Harboe M, Oettinger T, Wiker HG, Rosenkrands I, Andersen P (1996) Evidence for occurrence of the ESAT-6 protein in Mycobacterium tuberculosis and virulent Mycobacterium bovis and for its absence in Mycobacterium bovis BCG. Infect Immun Vol 64 No 1 Jan 1996 pp16-22 
Harding CV, Boom WH (2010) Regulation of antigen presentation by M. tuberculosis: a role for Toll-like receptors. Nat Rev Microbiol. Vol 8 No 4 Apr 2010 pp296-307

Hett EC, Chao MC, Steyn AJ, Fortune SM, Deng LL \& Rubin EJ (2007) A partner for the resuscitation-promoting factors of Mycobacterium tuberculosis. Mol Microbiol. Vol 66 No 3 Nov 2007 pp658-68

Huebner RE, Schein MF \& Bass JB Jr The tuberculin skin test. Clin Infect Dis. Vol 17 No 6 Dec 1993 pp968-75

Ishikawa E, Ishikawa T, Morita YS, Toyonaga K, Yamada H, Takeuchi O, Kinoshita T, Akira S, Yoshikai Y, Yamasaki S (2009) Direct recognition of the mycobacterial glycolipid, trehalose dimycolate, by C-type lectin Mincle. J Exp Med. Vol 206 No 13 Dec 2009 pp2879-88

Jafari C, Thijsen S, Sotgiu G, Goletti D, Domínguez Benítez JA, Losi M, Eberhardt R, Kirsten D, Kalsdorf B, Bossink A, Latorre I, Migliori GB, Strassburg A, Winteroll S, Greinert U, Richeldi L, Ernst M \& Lange C, Tuberculosis Network European Trialsgroup (2009) Bronchoalveolar lavage enzyme-linked immunospot for a rapid diagnosis of tuberculosis: a Tuberculosis Network European Trialsgroup study. Am J Respir Crit Care Med. Vol 180 No 7 Oct 2009 pp666-73

Jasmer RM, Nahid P \& Hopewell PC (2002) Latent Tuberculosis Infection N Engl J Med Vol 347 No 23 Dec 2002 pp1860-1866

Jo EK (2008) Mycobacterial interaction with innate receptors: TLRs, C-type lectins, and NLRs. Curr Opin Infect Dis. Vol 21 No 3 Jun 2008 pp279-86

Jo EK, Yang CS, Choi CH, Harding CV (2007) Intracellular signalling cascades regulating innate immune responses to Mycobacteria: branching out from Toll-like receptors. Cell Microbiol. Vol 9 N 5 May 2007 pp1087-98

Kana BD, Gordhan BG, Downing KJ, Sung N, Vostroktunova G, Machowski EE, Tsenova L, Young M, Kaprelyants A, Kaplan G \& Mizrahi V. (2008) The resuscitationpromoting factors of Mycobacterium tuberculosis are required for virulence and resuscitation from dormancy but are collectively dispensable for growth in vitro. Mol Microbiol. Vol 67 No 3 Feb 2008 pp672-84

Kenney RT, Rangdaeng S, Scollard DM (1987) Skin blister immunocytology. A new method to quantify cellular kinetics in vivo. J Immunol Methods Vol 97 No1 Feb 1987 pp101110

Khader SA, Cooper AM (2008) IL-23 and IL-17 in tuberculosis. Cytokine Vol 41 No 2 Feb 2008 pp79-83

Kinhikar AG, Verma I, Chandra D, Singh KK, Weldingh K, Andersen P, Hsu T, Jacobs WR Jr \& Laal S (2010) Potential role for ESAT6 in dissemination of M. tuberculosis via human lung epithelial cells. Mol Microbiol. Vol 75 No 1 Jan 2010 pp92-106

Kinhikar AG, Verma I, Chandra D, Singh KK, Weldingh K, Andersen P, Hsu T, Jacobs WR Jr, Laal S (2010) Potential role for ESAT6 in dissemination of M. tuberculosis via human lung epithelial cells. Mol Microbiol. Vol 75 No 1 Jan 2010 pp92-106

Kursar M, Koch M, Mittrucker HW, Nouailles G, Bonhagen K, Kamradt T, Kaufmann SH (2007) Cutting Edge: Regulatory $\mathrm{T}$ cells prevent efficient clearance of Mycobacterium tuberculosis. J Immunol Vol 178 No 5 Mar 2007 pp2661-2665

Lalor SJ, Dungan LS, Sutton CE, Basdeo SA, Fletcher JM, Mills KH (2011) Caspase-1processed cytokines IL-1beta and IL-18 promote IL-17 production by gammadelta 
and CD4 T cells that mediate autoimmunity. J Immunol. Vol 186 No 10 May 2011 pp5738-48

Lecoeur HF, Truffot-Pernot C, Grosset JH (1989) Experimental short-course preventive therapy of tuberculosis with rifampin and pyrazinamide. Am Rev Respir Dis. Vol 140 No 5 Nov 1989 pp1189-93

Leyten EM, Lin MY, Franken KL, Friggen AH, Prins C, van Meijgaarden KE, Voskuil MI, Weldingh K, Andersen P, Schoolnik GK, Arend SM, Ottenhoff TH, Klein MR (2006) Human T-cell responses to 25 novel antigens encoded by genes of the dormancy regulon of Mycobacterium tuberculosis. Microbes Infect Vol 8 No 8 Jul 2006 pp20522060

Liew FY, Xu D, Brint EK \& O'Neill LA (2005) Negative regulation of toll-like receptormediated immune responses Nat Rev Immunol. Vol 5 No 6 Jul 2005 pp446-58

Lin MY \& Ottenhoff TH. (2008) Not to wake a sleeping giant: new insights into hostpathogen interactions identify new targets for vaccination against latent $M$. tuberculosis infection. Biol Chem. Vol 389 No 5 May 2008 pp497-511

Mahairas GG, Sabo PJ, Hickey MJ, Singh DC, Stover CK (1996) Molecular analysis of genetic differences between Mycobacterium bovis BCG and virulent M. bovis. J Bacteriol Vol 178 No 5 Mar 1996 pp1274-82

Master SS, Rampini SK, Davis AS, Keller C, Ehlers S, Springer B, Timmins GS, Sander P, Deretic V (2008) Mycobacterium tuberculosis prevents inflammasome activation. Cell Host Microbe. Vol3 No4 Apr 2008 pp224-32

Menzies D, Dion MJ, Rabinovitch B, Mannix S, Brassard P \& Schwartzman K (2004) Treatment completion and costs of a randomized trial of rifampin for 4 months versus isoniazid for 9 months. Am J Respir Crit Care Med. Vol 170 No4 Mar 2004 pp445-9

Menzies D, Long R, Trajman A, Dion MJ, Yang J, Al Jahdali H, Memish Z, Khan K, Gardam M, Hoeppner V, Benedetti A \& Schwartzman K (2008) Adverse events with 4 months of rifampin therapy or 9 months of isoniazid therapy for latent tuberculosis infection: a randomized trial. Ann Intern Med. Vol 149 No 10 Nov 2008 pp689-97

Menzies D, Pai M, Comstock G (2007) Meta-analysis: new tests in the diagnosis of latent tuberculosis infection: areas of uncertainty and recommendations for research. Ann Intern Med Vol 146 No 5 Mar 2007 pp340-54

Mishra BB, Moura-Alves P, Sonawane A, Hacohen N, Griffiths G, Moita LF, Anes E (2010) Mycobacterium tuberculosis protein ESAT-6 is a potent activator of the NLRP3/ASC inflammasome. Cell Microbiol. Vol 12 No 8 Aug 2010 pp1046-63

Mukamolova GV, Turapov O, Malkin J, Woltmann G \& Barer MR (2010) Resuscitationpromoting factors reveal an occult population of tubercle Bacilli in Sputum. Am J Respir Crit Care Med. Vol 181 No 2 Jan 2010 pp174-80

Muñoz-Elias EJ, Timm J, Botha T, Chan WT, Gomez JE \& McKinney JD (2005) Replication dynamics of Mycobacterium tuberculosis in chronically infected mice. Infect Immun Vol 73 No 1 Jan 2005 pp546-551

Neyrolles O, Hernández-Pando R, Pietri-Rouxel F, Fornes P, Tailleux L, Barris Payan JA, Pivert E, Bordat Y, Aguilar D, Prévost M-C, Petit C \& Gicquel B (2006) Is adipose tissue a place for Mycobacterium tuberculosis persistence? Pub Lib of Sci One Vol 1 Dec 2006 pp1-9 
Nigou J, Zelle-Rieser C, Gilleron M, Thurnher M, Puzo G (2001) Mannosylated lipoarabinomannans inhibit IL-12 production by human dendritic cells: evidence for a negative signal delivered through the mannose receptor. J Immunol. Vol 166 No 12 Jun 2001 pp7477-85.

Nolan CM, Goldberg SV \& Buskin SE (1999) Hepatotoxicity associated with isoniazid preventive therapy: a 7-year survey from a public health tuberculosis clinic. JAMA Vol 281 No 11 Mar 1999 pp1014-8

Noss EH, Pai RK, Sellati TJ, Radolf JD, Belisle J, Golenbock DT, Boom WH, Harding CV (2001) Toll-like receptor 2-dependent inhibition of macrophage class II MHC expression and antigen processing by $19-\mathrm{kDa}$ lipoprotein of Mycobacterium tuberculosis. J Immunol. Vol 167 No 2 Jul 2001 pp910-8.

Ohno H, Zhu G, Mohan VP, Chu D, Kohno S, Jacobs WR Jr, Chan J (2003) The effects of reactive nitrogen intermediates on gene expression in Mycobacterium tuberculosis. Cell Microbiol. Vol 5 No 9 Sep 2003 pp637-48.

Pai M, Zwerling A \& Menzies D (2008) Systematic review: T-cell-based assays for the diagnosis of LTBI: an update. Ann Intern Med. Vol 149 No 3 Aug 2008 pp177-84

Pecora ND, Gehring AJ, Canaday DH, Boom WH, Harding CV (2006) Mycobacterium tuberculosis LprA is a lipoprotein agonist of TLR2 that regulates innate immunity and APC function. J Immunol. Vol 177 No 1 Jul 2006 pp422-9.

Peyron P, Vaubourgeix J, Poquet Y, Levillain F, Botanch C, Bardou F, Daffé M, Emile JF, Marchou B, Cardona PJ, de Chastellier C, Altare F (2008) Foamy macrophages from tuberculous patients' granulomas constitute a nutrient-rich reservoir for $\mathrm{M}$. tuberculosispersistence. PLoS Pathog. Vol 4 No 11 Nov 2008

Pieters J (2008) Mycobacterium tuberculosis and the macrophage: maintaining a balance. Cell Host Microbe. Vol 3 No6 Jul 2008 pp399-407

Platt JL, Grant BW, Eddy AA, Michael AF (1983) Immune cell populations in cutaneous delayed-type hypersensitivity. J Exp Med Vol 158 No 4 Oct 1983 pp1227-1242.

Polesky A, Farber HW, Gottlieb DJ, Park H, Levinson S, O'Connell JJ, McInnis B, Nieves RL, Bernardo J (1996) Rifampin preventive therapy for tuberculosis in Boston's homeless. Am J Respir Crit Care Med. Vol 154 No 5 Nov 1996 pp1473-7

Poulter LW, Seymour GJ, Duke O, Janossy G, Panayi G (1982) Immunohistological analysis of delayed-type hypersensitivity in man. Cell Immunol Vol74 No2 Dec1982 pp358369

Rees RJ \& Hart PD (1961) Analysis of the host-parasite equilibrium in chronic murine TB by total and viable bacillary counts. Br J Exp Pathol. Vol 42 Feb 1961 pp83-8.

Reichman LB, Lardizabal A \& Hayden CH (2004) Considering the role of four months of rifampin in the treatment of latent tuberculosis infection. Am J Respir Crit Care Med. Vol 170 No 8 Oct 2004 pp832-5

Renshaw PS, Lightbody KL, Veverka V, Muskett FW, Kelly G, Frenkiel TA, Gordon SV, Hewinson RG, Burke B, Norman J, Williamson RA \& Carr MD (2005). Structure and function of the complex formed by the tuberculosis virulence factors CFP-10 and ESAT-6 EMBO J. Vol 24 No 14 Jul 2005 pp2491-8.

Russell DG, Cardona PJ, Kim MJ, Allain S \& Altare F (2009) Foamy macrophages and the progression of the human tuberculosis granuloma. Nat Immunol. Vol 10 No 9 Sep 2009 pp943-948 
Russell-Goldman E, Xu J, Wang X, Chan J \& Tufariello JM (2008) A Mycobacterium tuberculosis Rpf double-knockout strain exhibits profound defects in reactivation from chronic tuberculosis and innate immunity phenotypes. Infect Immun. Vol 76 No 9 Sep 2008 pp4269-81.

Sarrazin H, Wilkinson KA \& Andersson J.Rangaka MX, Radler L, van Veen K, Lange C \& Wilkinson RJ (2009) Association between tuberculin skin test reactivity, the memory CD4 cell subset, and circulating FoxP3-expressing cells in HIV-infected persons. J Infect Dis Vol 199 No 5 Mar 2009 pp702-71

Sester M, Sotgiu G, Lange C, Giehl C, Girardi E, Migliori GB, Bossink A, Dheda K, Diel R, Dominguez J, Lipman M, Nemeth J, Ravn P, Winkler S, Huitric E, Sandgren A \& Manissero D (2011) Interferon- $\gamma$ release assays in the diagnosis of active TB: A systematic review and meta-analysis. Eur Respir J Vol 37 No 1 Jan 2011 pp100-11.

Shleeva MO, Bagramyan K, Telkov MV, Mukamolova GV, Young M, Kell DB \& Kaprelyants AS (2002) Formation and resuscitation of "non-culturable" cells of Rhodococcus rhodochrous and Mycobacterium tuberculosis in prolonged stationary phase. Microbiology Vol 148 No 5 May 2002 pp1581-1591

TBNET Mack U, Migliori GB, Sester M, Rieder HL, Ehlers S, Goletti D, Bossink A, Magdorf K, Hölscher C, Kampmann B, Arend SM, Detjen A, Bothamley G, Zellweger JP, Milburn H, Diel R, Ravn P, Cobelens F, Cardona PJ, Kan B, Solovic J, Duarte R, Cirillo DM, \& Lange C for the TBNET (2009) LTBI: latent tuberculosis infection or lasting immune responses to M. tuberculosis? A TBNET consensus statement Eur Respir J Vol 33 No5 May 200 pp956-973

Tufariello JM, Mi K, Xu J, Manabe YC, Kesavan AK, Drumm J, Tanaka K, Jacobs WR Jr \& Chan J (2006) Deletion of the Mycobacterium tuberculosis resuscitation-promoting factor Rv1009 gene results in delayed reactivation from chronic tuberculosis. Infect Immun. Vol 74 No 5 May 2006 pp2985-95.

Ulrichs T, Kosmiadi GA, Trusov V, Jörg S, Pradl L, Titukhina M, Mishenko V, Gushina N \& Kaufmann SH. (2004) Human tuberculous granulomas induce peripheral lymphoid follicle-like structures to orchestrate local host defence in the lung. J Pathol. Vol 204 No 2 Oct 2004 pp217-28.

Verhagen LM, van den Hof S, van Deutekom H, Hermans PW, Kremer K, Borgdorff MW \& van Soolingen D (2011) Mycobacterial factors relevant for transmission of tuberculosis. J Infect Dis. Vol 203 No 9 May 2011 pp1249-55

Villarino ME, Ridzon R, Weismuller PC, Elcock M, Maxwell RM, Meador J, Smith PJ, Carson ML, Geiter LJ (1997) Rifampin preventive therapy for tuberculosis infection: experience with 157 adolescents. Am J Respir Crit Care Med. Vol 155 No 5 May 1997 pp1735-8

Voskuil MI, Schnappinger D, Visconti KC, Harrell MI, Dolganov GM, Sherman DR, Schoolnik GK (2003) Inhibition of respiration by nitric oxide induces a Mycobacterium tuberculosis dormancy program. J Exp Med. Vol 198 No 5 Sep 2003 pp 705-13.

WHO (2001) WHO warns against the use of inaccurate blood tests for active tuberculosis http://www.who.int/mediacentre/news/releases/2011/tb_20110720/en/index.h tml

World Health Organization Tuberculosis Fact-sheet http://www.who.int/mediacentre/factsheets/fs104/en/index.html 
Zvi A, Ariel N, Fulkerson J, Sadoff JC \& Shafferman A. (2008) Whole genome identification of Mycobacterium tuberculosis vaccine candidates by comprehensive data mining and bioinformatic analyses. BMC Med Genomics. Vol 1 May 2008 pp18 


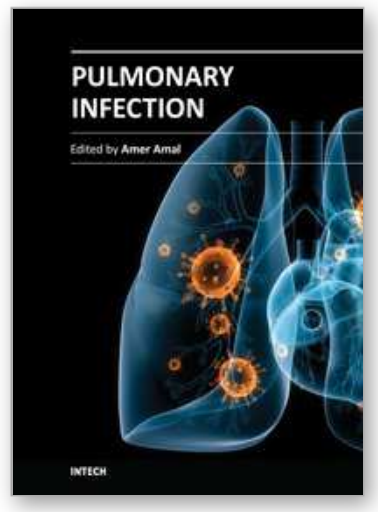

\author{
Pulmonary Infection \\ Edited by Dr. Amer Amal
}

ISBN 978-953-51-0286-1

Hard cover, 128 pages

Publisher InTech

Published online 14, March, 2012

Published in print edition March, 2012

Pulmonary infections are notorious in causing considerable morbidity and mortality. Caused by bacteria, viruses or fungi, respiratory infections require distinct knowledge of recent advances in pathogenesis. Progress in the understanding of immunopathogenesis of Acinetobacter baumannii infection will explain how an atypical organism establishes infection. The chapter regarding pulmonary nontuberculous mycobacterial infections in the State of Para depicts a unique study in an endemic region for tuberculosis in North of Brazil. The diagnosis and treatment of latent tuberculosis is a formidable challenge. Thus, new developments in diagnosis and treatment of latent tuberculosis are included in this book. Challenging in their diagnosis, nontuberculous mycobacterial pulmonary diseases require special education for management. The problems of respiratory infections in the immunocompromised host are increasing in numbers and in resilience to treatment. Therefore, the chapter describing the host immune responses against pulmonary fungal pathogens comes as a necessary section in this book. The insight brought forth from this book can be valuable for both clinicians and scientists.

\title{
How to reference
}

In order to correctly reference this scholarly work, feel free to copy and paste the following:

Dimitrios Basoulis, Georgia Vrioni, Violetta Kapsimali, Aristeidis Vaiopoulos and Athanasios Tsakris (2012). Latent Tuberculosis: Advances in Diagnosis and Treatment, Pulmonary Infection, Dr. Amer Amal (Ed.), ISBN: 978-953-51-0286-1, InTech, Available from: http://www.intechopen.com/books/pulmonary-infection/latenttuberculosis-new-developments-in-diagnosis-and-treatment

\section{INTECH}

open science | open minds

\section{InTech Europe}

University Campus STeP Ri

Slavka Krautzeka 83/A

51000 Rijeka, Croatia

Phone: +385 (51) 770447

Fax: +385 (51) 686166

www.intechopen.com

\section{InTech China}

Unit 405, Office Block, Hotel Equatorial Shanghai

No.65, Yan An Road (West), Shanghai, 200040, China 中国上海市延安西路65号上海国际贵都大饭店办公楼 405 单元

Phone: +86-21-62489820

Fax: +86-21-62489821 
(C) 2012 The Author(s). Licensee IntechOpen. This is an open access article distributed under the terms of the Creative Commons Attribution 3.0 License, which permits unrestricted use, distribution, and reproduction in any medium, provided the original work is properly cited. 